\title{
Development of an Automated Approach for Updating of the Annual Runoff Module Map
}

\author{
N.V.Arefiev ${ }^{1}$, N.S.Bakanovichus ${ }^{2}$, A.A.Lyalina ${ }^{2}$, N.V.Sudakova ${ }^{2}$, T.S.Ivanov ${ }^{3}$, \\ S.P.Kotlyar ${ }^{3}$, M.V.Petroshenko ${ }^{3}$ \\ ${ }^{1}$ Saint-Petersburg Polytechnical University, Civil Engineering Institute \\ Address: Polytechnicheskaya str., 29, Saint-Petersburg, 195251, Russia; \\ ${ }^{2} J S C$ VNIIG, Laboratory of Reservoirs thermic and ice thermic \\ Address: Gjatskaya str., 21, Saint-Petersburg, 195220, Russia; \\ ${ }^{3}$ JSC VNIIG, Laboratory of Geographic Information Systems and Technologies \\ Address: Gjatskaya str., 21, Saint-Petersburg, 195220, Russia
}

\begin{abstract}
Several Russian Hydropower Design and Research Institutes have recently fulfilled studies of hydropower potential estimation for NorthWest, Caucasian and Angara River's regions in Russia. An approach to automate the calculation of river flow characteristics, based on the usage of annual flow rate map, was proposed and tested by the authors for the aims of the studies.

Annual river flow characteristics together with the terrain data are the most important data sources for evaluation of the hydropower potential.

A set of requirements was made for the approach and for automation of annual flow rate maps creation in order to provide ability for updates in every 5-10 years.

A problem of lack of hydrological data for small and medium sized rivers was faced. To determine the hydrological characteristics the Russian code specification "Determination of Design Hydrological Performance" was used for the conditions of the lack of hydrological data, methods of spatial interpolation were also used.

To solve the problems it is necessary to define the parameters of the annual flow distribution: average annual flow, variation coefficient, coefficient of skewness.

Mapping is based on the assumption of a smooth change of annual flow rate for any territory in accordance with the distribution of climatic and physiographic factors (topography, soil, groundwater depth, etc.).

Milestones of flow rate mapping included: preparation of hydrological initial data; creating of the updated flow rate maps; determination of the corrections to the influence of local azonal factors; estimation of the accuracy of flow characteristics calculations.

In order to update the annual flow rate maps a special GIS application "Hydrologist" was created. The GIS application includes computer-assisted tool for processing the hydrological data, import/export tools, tools for analysis of area zoning data, tools for analysis of annual flow rate values in centroids of drainage-basins, location of water stage gauges, also the old and updated flow rate maps.

The article deals with the approach description, main problems that were faced and presenting the results.

The technology has been applied for North-West, Volga and Siberian Federal Districts in Russia. Comparison of the created annual flow rate map with the previously used map shows that the updated map is better of acquiring hydrological data for small and medium sized rivers.
\end{abstract}

Keywords: runoff module map, GIS-technologies.

\section{INTRODUCTION}

Large-scale studies for identifying locations of prospective small hydropower plants (SHPP) are currently conducted in Russia [1]. Within the scope of works authors have developed automated approaches for hydrologic data calculations. Hydropower potential calculations and SHPP siting were performed based on this hydrological characteristic.
According to analysis of world experience in automated hydropower potential calculations, the most common hydrological characteristic used for this kind of works is values of mean annual flow [2].

Authors have analyzed possible ways to obtain the annual flow rate data of Russian rivers, and the decision to update the runoff module map was made (Fig. 1). 


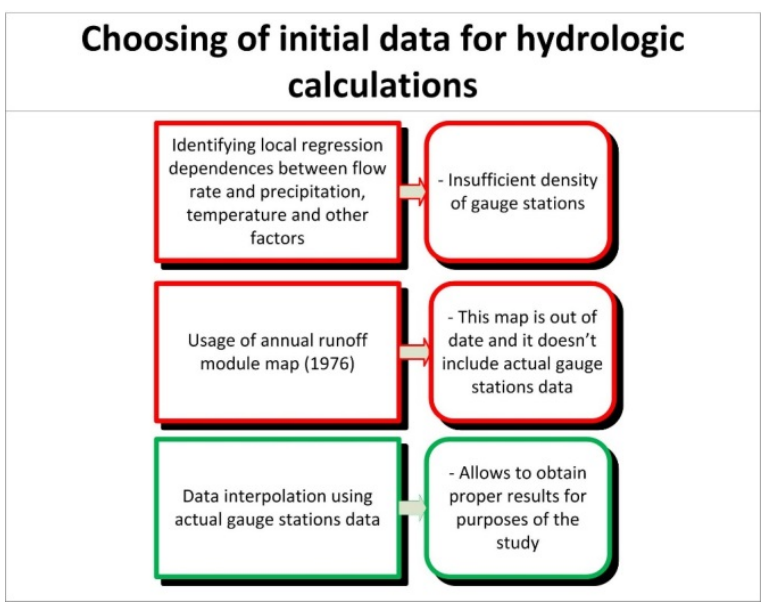

Fig. 1. Choosing of initial data for hydrologic calculations.

Development of software application was needed to provide the ability to update runoff module map every 5-10 years. This application allows storing initial data for calculations, provides tools for hydrologic data processing, tools for import/export of hydrologic records and other information stored, such as runoff module in watersheds gravity centers, locations of gauge stations, previous and updated versions of runoff module maps.

Taking into account insufficient exploration degree of medium and small rivers in Russia, method of spatial interpolation was used to obtain hydrologic parameters (this method is recommended by regulatory document [3] in case of a lack of hydrological measurements).

\section{PROPOSED APPROACH}

To solve the problems of the research, calculations of distribution of annual flow rate parameters are needed. So, mean annual flow rate, spread coefficient and ratio of skewness coefficient to spread coefficient should be calculated $[4,5]$.

The annual flow rate distribution depends on zonal climatic factors changes and elements of natural landscape [6]. Climatic zones and altitudinal zonation gives grounds for creating flow rate distribution maps. An ability of creating runoff module maps is based on an assumption of smooth spatial changes of annual mean flow rate in accordance with distribution of climatic and physiographic factors [7].

The main work stages of creating maps of annual flow rate distribution are shown on Fig.2:

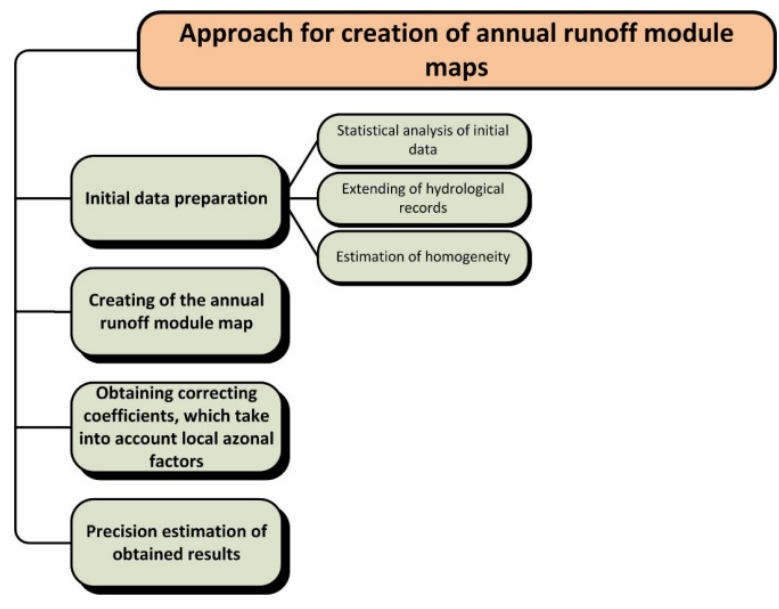

Fig. 2. Approach for creation of annual runoff module maps.

Creation of annual flow rate distribution maps was performed based on hydrological data of medium rivers with watershed area from 2000 to $50000 \mathrm{~km}^{2}$, because flow rate of these rivers depends on zonal factors. Hydrologic records were extended for all gauge stations with period of measurements more than 6 years using method of regression dependence.

Excluding of systematic decrease of extended hydrologic records dispersion was achieved by using correcting value of annual mean flow rate [4]:

$$
Q_{i}^{\prime}=\left(Q_{i}-Q_{\text {mean }}\right) / R+Q_{\text {mean }},
$$

Where:

$Q_{\mathrm{i}}{ }^{\prime}$ - annual values of hydrologic characteristics, calculated using regression equations,

$Q_{\text {mean }}$ - mean value of hydrologic records for the same period as in gauge station analogue

$R$ - coefficient of correlation between studying river flow rate and flow rate in gauge station analogue

Annual flow rate distribution values were normalized to watershed gravity center of the river.

In purpose to create contour maps of flow rate distribution parameters the GIS-based WEBapplication was developed. This application allows user to place an interpolative conjunctions between the centers of the watersheds. The necessity of adding the conjunction is determined by user and is based on mean watershed altitude.

The interpolation is carried out only between watersheds gravity centers, which are located in similar climatic and zonal conditions. Interpolation was performed by taking into account distance between points and altitude zonation.

Figure 3 shows a map fragment with interpolative conjunctions. 


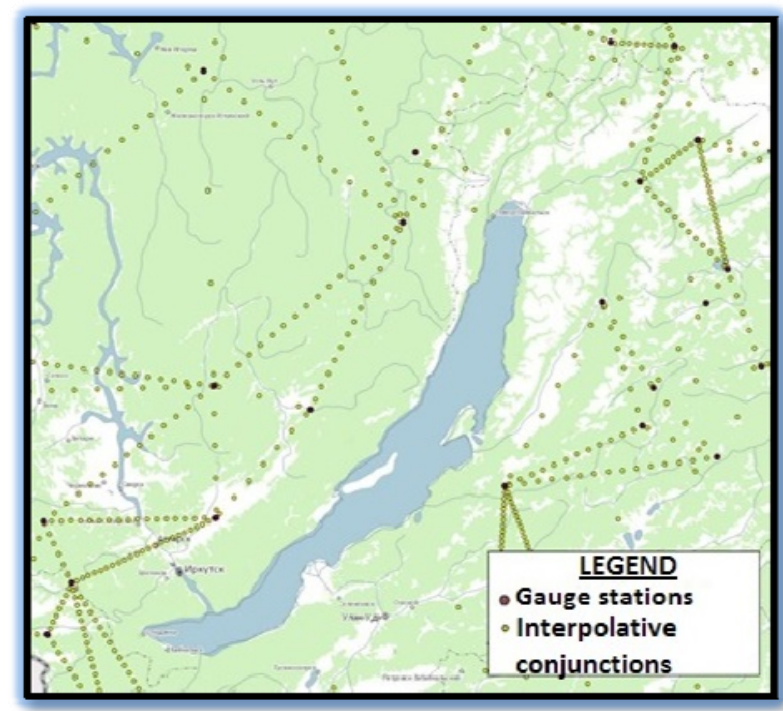

Fig. 3. Interpolation of annual average runoff module values (Russia map fragment).

After adding the conjunctions, added points were stored in the database.

Contour maps of flow rate distribution parameters were created using obtained values of runoff module in watersheds' gravity centers and interpolated values.

The accuracy of contours delineating and precision of calculated values of runoff module are depend on the river network density, smoothness of surface topography changes, precision of specifying watersheds gravity centers and spatial structure of annual flow rate.

Authors have plotted charts of flow rate distribution parameters versus watershed area and obtained deviations of small rivers' flow rate from zonal mean annual flow rate. Taking into account obtained charts; correcting coefficients for runoff module of small rivers with lack of hydrological measurements were obtained.

For mountainous study areas a local dependences between runoff module and watershed altitude were identified: $q=f\left(H_{w t r s h d}\right)$.

Changes of spread coefficient $\left(C_{v}\right)$ and mean annual flow rate depend on latitude. Based on a $C_{v}$ values, a map of rivers annual flow rate variability were created.

Spatial generalization of skewness coefficient $\left(C_{s}\right)$ is hardly possible in most cases, because of significant random errors of this parameter caused by insufficiency of initial data. Therefore, the ratio $\left(C_{s} / C_{v}\right)$ was calculated and this parameter was regionalized.

Mean annual flow rate for control point located on a plain territory can be obtained using linear interpolation between contours [8]. But in case of significant elevation changes between runoff module contours, the linear interpolation will give incorrect results. To avoid this problem, runoff module can be obtained using following equation (in case of two or more contours intersecting studying watershed) [3]:

$q_{\mathrm{cp}}=\left(q_{1} \cdot A_{1}+q_{2} \cdot A_{2}+\cdots+q_{n} \cdot A_{n}\right) / A$,

Where:

$q_{1}, q_{2}, \ldots, q_{n}-$ mean values of runoff module between adjoining contours;

$A_{1}, A_{2}, \ldots, A_{n}$ - watershed areas between contours;

$A$ - aggregated watershed area in point of interest.

Local azonal factors affecting runoff module should be taken into account for small rivers. These factors consist of incomplete draining of ground waters, karst, watershed landform features, geology aspects and some other aspects.

Depending on ratio of surface to subsurface watershed area, annual mean flow rate of rivers, especially small-sized, may vary upwards (if subsurface watershed is larger than surface watershed) or downwards (in case of karst). Flow rate module of rivers located in karst regions can be reliably obtained only through hydrometric measurements or using method of hydrological analogy [9].

\section{APPROBATION OF PROPOSED APPROACH}

This section represents an approbation of approach described above with North-West federal district as a study area.

First, gauge stations data was gathered and stored in a database and long-term hydrologic records were analyzed. As a result of the analysis, it was considered to take into account only gauge stations with the natural flow formation conditions. Also, gauge stations with statistically unreliable or heterogeneous by Student's test or by F-test hydrologic records were excluded. After exclusion, 482 gauge stations remained and were used for runoff module calculations. Most of gauge stations on the study area $(60.3 \%)$ have hydrologic records for more than 30 year period.

Extending of short-period hydrologic records was performed for all gauge stations with 6 and more years of hydrologic measurements with the help of charts of annual flow rate correlation. Coefficients of correlation to annual flow rate in most cases $(45.5 \%)$ vary from 0.70 to 0.80 , in $39.8 \%$ - from 0.81 to 0.90 and in $(14.7 \%)$ - from 0.91 to 0.99 .

A fragment of summary table containing list of analogues, regression equations and coefficients of correlation is shown in Table 1.

Extended hydrologic records had passed verification of homogeneity by Student's test and by F-test. Calculated relative standard deviation for annual mean flow rate $-(1.4 \div 12.3) \%$, for $C_{v}-(1.0 \div$ $12.2) \%$.

The maps of flow rate module, variability of annual mean flow rate and ratio $C_{s} / C_{v}$ were created. Gauge 
stations with anomalous flow rate values caused by local physiographic factors were excluded.

In regions with absence of hydrologic measurements, contours were delineated based on precipitation data, orography and climatic parameters.

Fragment of runoff module map is shown on the Figure 4.
Zonal distribution of annual flow rate correlates with distribution of precipitations and evaporation.

Runoff module varies largely on study area - from 2.9 to $37.21 /\left(\mathrm{sec}^{*} \mathrm{~km}^{2}\right)$. This large range of values is determined by significant size of study area (1686968 $\mathrm{km}^{2}$ ). In addition, mountainous regions of Ural and Kola Peninsula determine the wide range of runoff module values.

TABLE 1

FRAGMENT OF SUMMARY TABLE "RIVERS-ANALOGUES, REGRESSION EQUATIONS AND COEFFICIENTS OF CORRELATION

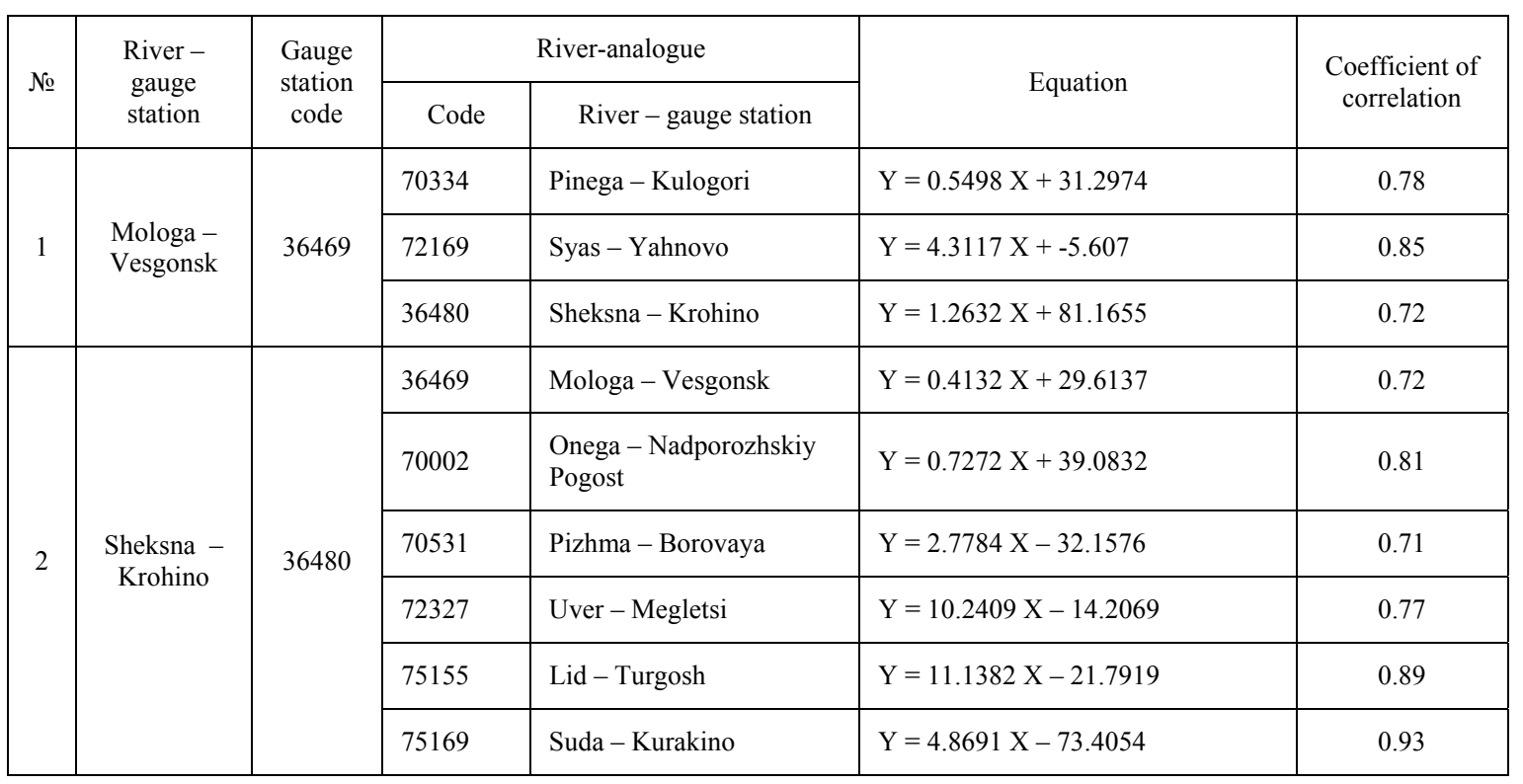

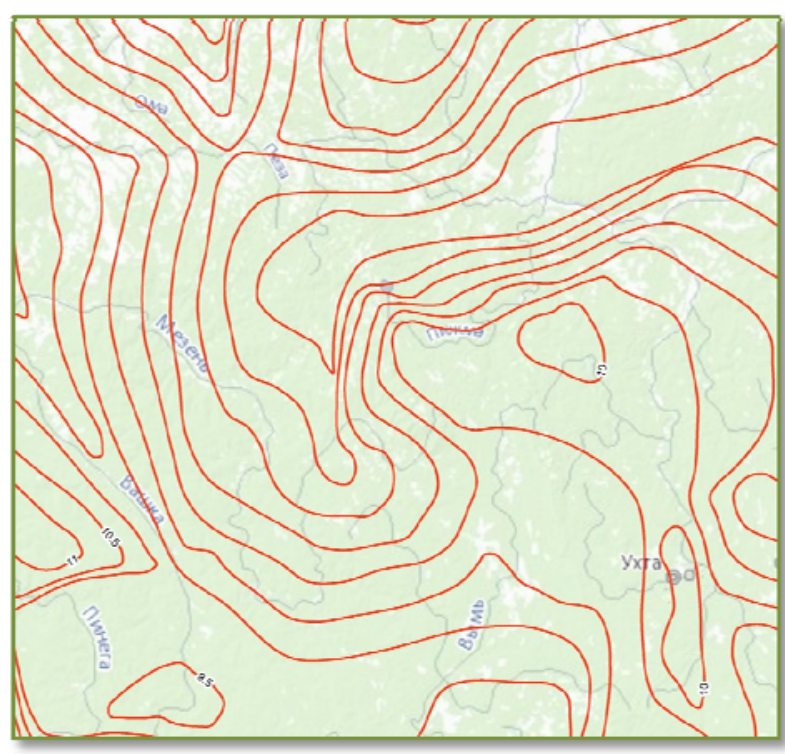

Fig. 4. Fragment of the annual runoff module map on North-West federal district study area.

Calculated runoff module values were compared with actual gauge stations data (25 gauge stations were analyzed). Mean deviation for runoff module -
$6.0 \%$, minimum deviation $-0.7 \%$, maximum $-24.2 \%$. In general, obtained runoff module values are proper.

The approach described above was applied for several federal districts in Russia. Correcting coefficients for small rivers and dependences between runoff module and flow formation factors were identified. This approach allows to calculate annual flow rate parameters of rivers and to make a preliminary justification of stream reaches hydropower potential development [10].

Also, the comparison of calculated runoff module values with existing runoff module map (was created in 1976 year [11]) was performed. Results of comparison are shown on the Figure 5 and Figure 6.

As shown on Figure 5, maximum deviations of runoff module are less than $10.0 \mathrm{l} /\left(\mathrm{sec}^{*} \mathrm{~km}^{2}\right)$, mean deviations - $3.0 \mathrm{l} /\left(\mathrm{sec}^{*} \mathrm{~km}^{2}\right)$. Maximum deviations appeared in Ural foothills.

To provide ability for updating runoff module maps, WEB-application was developed. The architecture of the application is shown on Figure 7. 


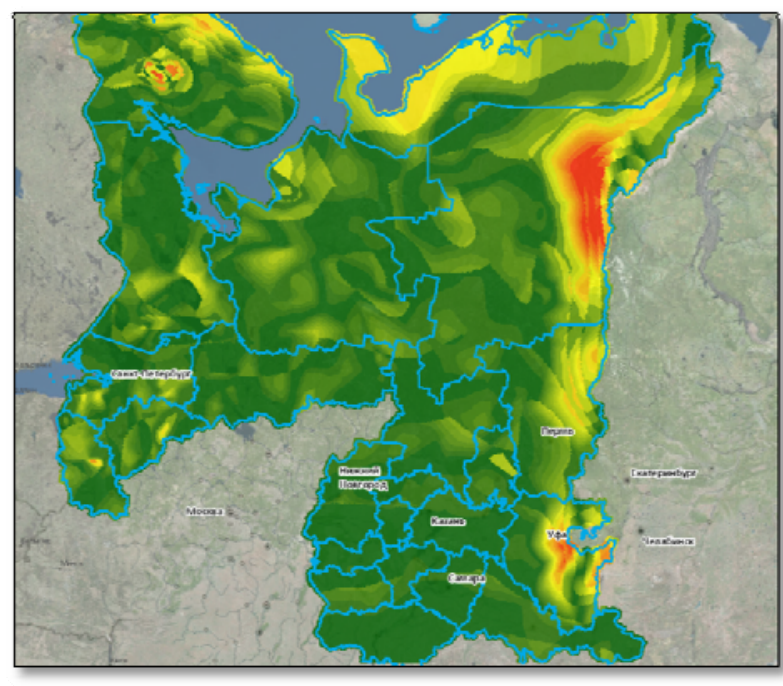

Fig. 5. Differences between runoff module values (comparison of 1976 and 2014 year data).

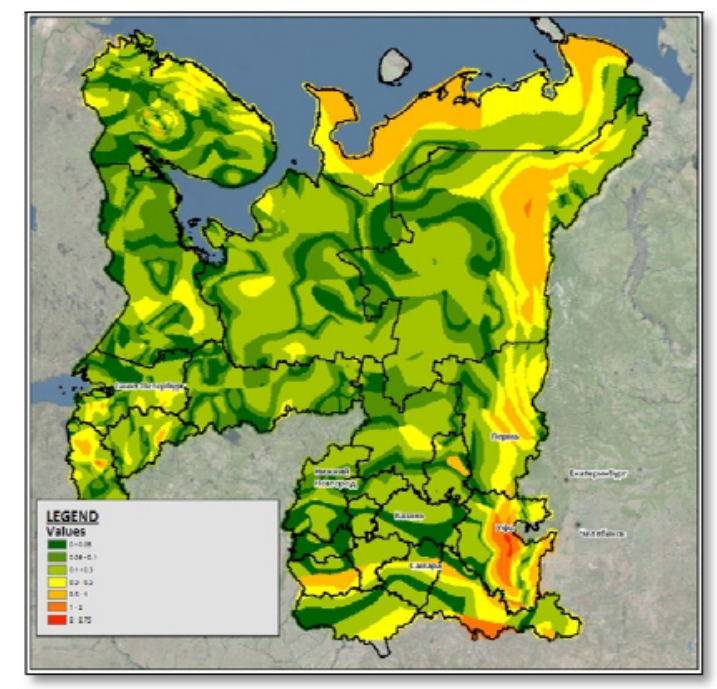

Fig. 6. Relative differences between runoff module values (comparison of 1976 and 2014 year data).

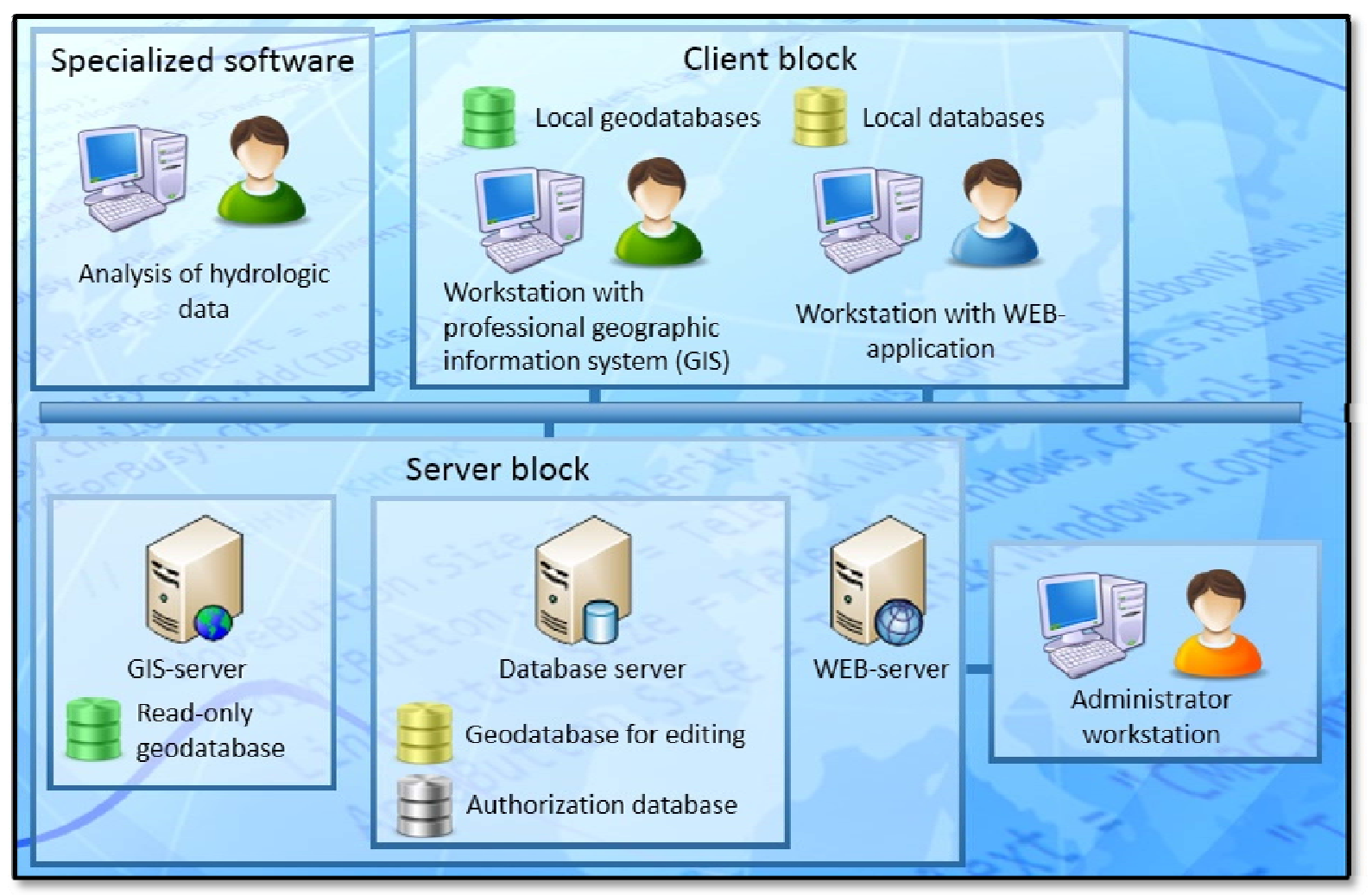

Fig. 7. Architecture of developed WEB-application

\section{CONCLUSION}

The approach for creating runoff module maps was developed based on Russian regulatory document [3]. The approbation of proposed approach was carried out. Runoff module map for several federal districts in Russia was created; obtained results were compared with previous versions of runoff module map and with gauge stations data. Also, maps of $C_{v}$ and $\left(\mathrm{C}_{\mathrm{s}} / \mathrm{C}_{\mathrm{v}}\right)$ distribution were created. Described approach allows calculating runoff module for all Russian territory and provides the ability to update the runoff module map every 5-10 years using up-to-date gauge stations data. 


\section{REFERENCES}

[1] Programma razvitija maloj gidrojenergetiki RusGidro [on-line resurs]. URL: http://www.rushydro.ru/industry/res/tidal/ (Data obrashhenija: 15.04.2013).

[2] Arefiev, N., Badenko, N., Ivanov, T., Kotlyar, S. Nikonova, O., Oleshko, V. Hydropower Potential Estimations and Small Hydropower Plants Siting: Analysis of World Experience (2015) Applied Mechanics and Materials, 725-726, pp. 285292.

[3] SP 33-101-2003 «Opredelenie osnovnyh raschetnyh gidrologicheskih harakteristik»/M.: FGUP CPP, 2004.

[4] Vladimirov A.M. Sbornik zadach i uprazhnenij po gidrologicheskim raschetam/ V.S. Druzhinin - SPb: Gidrometeoizdat, 1992.

[5] Sikan A.V. Metody statisticheskoj obrabotki gidrometeorologicheskoj informacii - SPb: RGGMU, 2007.
[6] Davydov L.K. Gidrografija SSSR (vody sushi). Chast' II. Gidrografija rajonov. L.: Izdatel'stvo Leningradskogo Universiteta, 1955

[7] Sokolov A.A. Gidrografija SSSR (vody sushi). L: Gidrometeorologicheskoe izdatel'stvo, 1964.

[8] Fiziko-geograficheskoe rajonirovanie SSSR. Harakteristika regional'nyh edinic/pod redakciej prof. N.A. Gvozdeckogo.M.: Izdatel'stvo Moskovskogo Universiteta, 1968

[9] SP 11-103-97 Inzhenerno-gidrometeorologicheskie izyskanija dlja stroitel'stva /M.: PNIIIS Gosstroja Rossii, 1997.

[10] SP 47.13330.2012 "Inzhenernye izyskanija dlja stroitel'stva. Osnovnye polozhenija" Aktualizirovannaja redakcija SNIPa 11-02-96/ M.: Minregion Rossii, 2013.

[11] Posobie po opredeleniju raschetnyh gidrologicheskih harakteristik - L: Gidrometeoizdat, 1984. 